\title{
Sulfamethoxazole Crystalluria
}

\author{
Kumarpal Shrishrimal, MD, MS, Jeffrey Wesson, MD, PhD \\ Medical College of Wisconsin, Milwaukee, Wisconsin
}

\section{To the Editor:}

We report a patient who presented with acute kidney injury after treatment with linezolid and Bactrim DS, 2 tablets twice a day, for a leg wound. The patient also was receiving furosemide for leg edema. Fractional excretion of sodium was $46 \%$, and kidney ultrasound showed normal-sized kidneys with no hydronephrosis. Urinalysis showed $\mathrm{pH}$ of 5.5 and no protein, blood, leukocyte esterase, or nitrite. Polarized urine microscopy showed birefringent pleomorphic crystalluria (Fig 1A). Some crystals had the characteristic "coffin lid" appearance suggesting struvite (triple phosphate) crystals. Others had notched edges suggestive of uric acid crystals. Still other crystals formed a rosette.

The urine $\mathrm{pH}$ of 5.5 made struvite less likely, and the serum uric acid level of $6 \mathrm{mg} / \mathrm{dL}$ made uric acid unlikely. Infrared spectroscopy was performed on the urine sample, and the absorbance pattern confirmed the diagnosis of sulfamethoxazole crystalluria (Fig 1B). Figure 1B shows the background absorbance of the control urine with spikes of $N$-acetyl sulfamethoxazole.

Sulfa crystals can be seen with both sulfamethoxazole and sulfadiazine. Sulfadiazine crystalluria appears in a volume-depleted state during administration of higher doses of both oral and intravenous formulations. The major metabolite of sulfamethoxazole in urine is $\mathrm{N}$-acetyl sulfamethoxazole. The crystals generally are pleomorphic and form in acidic urine. Treatment involves stopping the drug treatment and alkalinizing the urine with intravenous fluids. ${ }^{1-3}$

We are pleased to share a case in which urine microscopy and infrared spectroscopy were useful in making the diagnosis of sulfamethoxazole crystalluria.

\section{Acknowledgements}

Financial Disclosure: The authors declare that they have no relevant financial interests.

\section{References}

1. Berns JS, Cohen RM, Stumacher RJ, Rudnick MR. Renal aspects of therapy for human immunodeficiency virus and associated opportunistic infections. J Am Soc Nephrol. 1991;1(9):1061. [PubMed: 1912406] 
2. Buchanan N. Sulphamethoxazole, hypoalbuminaemia, crystalluria, and renal failure. Br Med J. 1978;2(6131):172.

3. Paap CM, Nahata MC. Clinical use of trimethoprim/sulfamethoxazole during renal dysfunction. DICP. 1989;23(9):646. [PubMed: 2678767] 

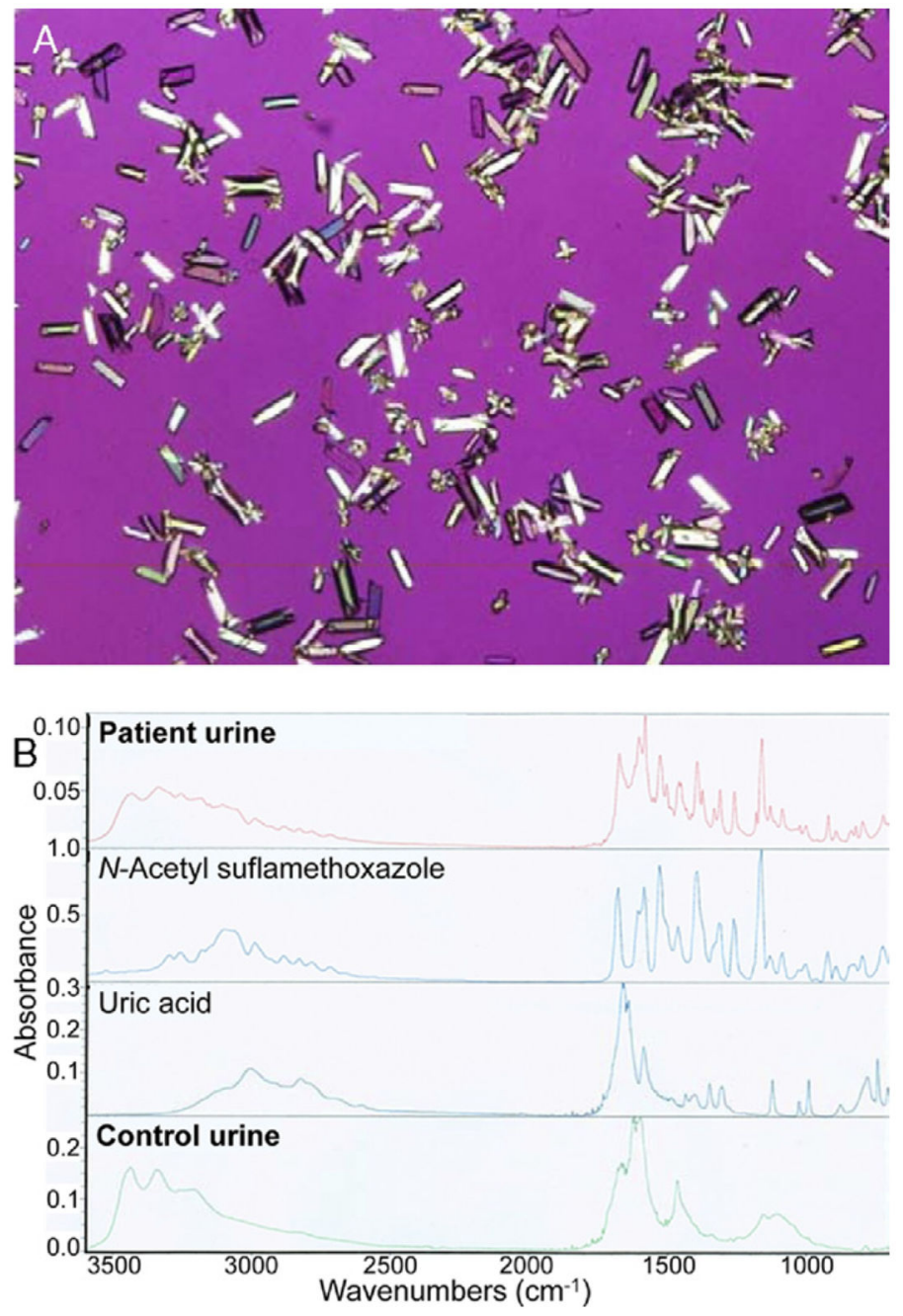

Figure 1.

(A) Birefringent pleomorphic crystalluria on polarized microscopy, and (B) infrared spectroscopy of urine sample: absorbance pattern confirms the diagnosis of sulfamethoxazole crystalluria. 